Portland State University

PDXScholar

\title{
Building a Sustainable Business Model through Technology Entrepreneurship: An Analysis of Business Models from a System and a System of Systems Perspective
}

\author{
Gary Langford \\ Portland State University, gary.langford@pdx.edu \\ Teresa Langford \\ Portland Community College
}

Follow this and additional works at: https://pdxscholar.library.pdx.edu/etm_fac

Part of the Technology and Innovation Commons

Let us know how access to this document benefits you.

\section{Citation Details}

G. Langford and T. Langford, "Building a Sustainable Business Model through Technology Entrepreneurship: An Analysis of Business Models from a System and a System of Systems Perspective," 2019 Portland International Conference on Management of Engineering and Technology (PICMET), Portland, OR, USA, 2019, pp. 1-12.

This Article is brought to you for free and open access. It has been accepted for inclusion in Engineering and Technology Management Faculty Publications and Presentations by an authorized administrator of PDXScholar. Please contact us if we can make this document more accessible: pdxscholar@pdx.edu. 


\title{
Building a Sustainable Business Model through Technology Entrepreneurship: An Analysis of Business Models from a System and a System of Systems Perspective
}

\author{
Gary Langford ${ }^{1}$, Teresa Langford ${ }^{2}$ \\ ${ }^{1}$ Engineering \& Technology Management, Portland State University, Portland, Oregon, USA \\ ${ }^{2}$ Business and Accounting Department, Portland Community College, Portland, Oregon, USA
}

\begin{abstract}
Case study methods are used to identify key elements of business models in highly competitive environments. Small businesses, in particular, must rely on entrepreneurial prowess and innovation, adapt to their environment, have sufficient resources, and skillfully manage project outcomes in entrepreneurial start-up situations. This research hypothesized that a problem faced by entrepreneurial organizations is due to the fundamental flaws and poor adaptability of their business models to satisfy needs of customers and prospective customers. The problem is that the flow of value from business to customer was different from the flow of value from business to user. Two kinds of business models were examined - for-profit and nonprofit. Each business model is expressed and compared in terms of their inherent systemic nature as both a system and as a system of systems. A systems approach is used to identify the essential requirements for building a sustainable business model through a mix of technology innovations for products and services. This paper reveals why sustainable entrepreneurial businesses can be built regardless of given their status as forprofit or non-profit. The advantages and disadvantages of forprofit and non-profit businesses are discussed.
\end{abstract}

\section{INTRODUCTION}

In the late 1930s, Chester Barnard [1] pioneered the notion that a business can be adequately considered as a system. Barnard characterized a business as a system of complex human interdependencies expressed by motivation and behavior, and cooperation, led by superior intellects. Several years after Barnard's lectures and writings, systems' theorists advocated principles related to holism, boundaries, hierarchy, mutuality, equilibrium, equifinality, and entropy [2-8] to advocate a General Systems Theory [9]. For the past 85 years, characterizing a business as a system has been a persistent theme in academic and business-as-practice literature.

This paper applies a model-based systems approach [10-11] (MBSA) to analyze and evaluate six case studies of martial arts businesses in Taekwondo (Korean way of fists and feet). In the United States there were 73,000 small businesses employing 73,000 people instructing 1.8 million participants who paid $\$ 580$ million in 2015 (\$326 million for instruction and \$224 million for equipment) $[12,13]$ The mix of Taekwondo participants are about equal male/female, with $40 \%$ of revenue derived from participants below age of 1 ; and among children aged 6-12 [14]. Martial arts is the third-most popular physical activity - with instruction emphasizing health, confidence, and competition [15].

\section{BACKGROUND}

The three primary aspects of martial arts - mind, strategy, competition - form the value gained from participating in this Olympic Sport. Competition is the most visible and expensive aspect of the value structure. Basic gear costs each participant about $\$ 100$ every few years [12]. Additionally, competition has driven the martial arts businesses to either invest $\$ 10,000$ to $\$ 25,000$ in equipment every $8-10$ years or rent at the rate of $12 \%$ of retail price for a period of 30 days [16]. With the advent of new digital technology, that initial investment can now be in excess of $\$ 100,000$ [17]. Competition is rapidly increasing the expenses for both the business and the participants. Recent technology advances in judging competitive matches have eliminated arbitrary decisions, bad referring, and missed split-second point-worthy strikes by competitors. Sensor-laden protective gear worn by competitors detects and records strikes of less than 30-40 millisecond durations - sufficient to score a point under various circumstances. The purchase price per competitor for such digital technology is greater than $\$ 2,000$ (with a 5,000 strike or 1-year warranty) [17]. The business owner must use an additional $\$ 4,000$ in equipment to record the points and replay matches to help participants train and improve [17]. Even for the smaller Dojang (typical training facility), the expenses to compete in tournaments is beginning to price businesses and participants out of the market for martial arts. Similar to other sports, the cost of participation can limit the access and change the demographics of the sport. The effect of new de facto "standards" increasingly means substantially higher expenses. In martial arts, the adrenaline demand from competition has led to technical innovation that in turn invokes exploitation for sales and profits. This process is not without merit. There is an insistent and peremptory call for safety and fairness. Technological innovation, at a cost, provides for safety and digital innovation, at a cost, provides for fairness. Both safety and digital innovation are socially desirable. In martial arts, digital technology is expensive by any measure. 


\section{A. The business challenge}

Owners of martial arts businesses need to make an initial investment of up to $\$ 100,000$ [17] to achieve revenues from $\$ 2,000$ to $+\$ 70,000$ per year [12]. If there are nominally 35 participants in a typical training facility (Dojang), the cost to access desirable tournament technology can impose recurring expenses as high as $\$ 74,000$ per year - essentially bankrupting most martial arts businesses [12]. Historically, the business owners have tried to avoid these expenses or by charging higher customer fees to reduce business expenses, by trying desperately to reduce expenses, or by dropping out of tournament competition.

\section{B. For-profit and nonprofit taekwondo businesses}

There is a profound difference between for-profit and nonprofit taekwondo businesses. The typical distinction is that nonprofits are owned by the public and therefore reinvest in the business and do not distribute profits. Owners of for-profit taekwondo businesses manage the business to generate income for themselves. To survive, both kinds of businesses depend on membership fees and sales of products and services. The primary difference is the mission statement. The lead instructor(s) in the non-profits desire to give participants the benefit of their experience to continue the tradition of taekwondo to advance the mental attitudes and thinking, the competitive nature through tournaments, and the strategies of attack and defense. The lead instructor(s) in the for-profit businesses are primarily interested on being compensated for their transferring skills to participants. Those skills may emphasize one or all of the traditions of taekwondo, i.e., to advance the mental attitudes and thinking, the competitive nature through tournaments, and the strategies of attack and defense. The digital curtain may be closed for the non-profit organizations because there may be an insufficiency of funds to purchase the digital technology. The focus for the nonprofits may be to carry on with the traditions of taekwondo by hosting local tournaments that are refereed using the "old" non-digital traditions. The digital curtain may be closed for the for-profit organizations because of a similar insufficiency of funds. The for-profit organizations may also join in local competitions with for-profit and nonprofit participants. In either instance, both the for-profit and the nonprofit organizations will deny their participants to betterment in tournament skills with a closed digital curtain.

\section{STATEMENT OF THE PROBLEM}

Owners face the unenviable choice of adopting the technology and risking going out of business for lack of profit, or not providing access to the technology and losing participants to larger martial arts corporations who have the incomes to absorb some costs amortized over their 500 to 1,000 students. Regardless of the size of the Taekwondo organization, the increased financial burden to keep the digital curtain open is becoming a problem.

If the digital curtain closes on any portion of our society, the result is social exclusion for those prevented from accessing the digital technology. The historical consequences include depriving those afflicted of valuable resources that are essential for maintaining civility; loss to the economy from participation by the disenfranchised; and loss of self-esteem which results in poor skills, low incomes, high crime, ill-health, and breakdown of family support which causes a problem of the excluded losing wage-opportunites spatial isolation of certain groups [18].

The problem is not a characterization as implied by the digital divide. Closing the digital curtain widens the divide, while an open digital curtain provides ubiquitous, unfettered access to all.

\section{The problem is determining how to control the digital curtain.}

The problem is manifest in increased advertising by businesses for participants aged 3-5. Tournament competition at the local level can begin at age 12 [15]. Businesses profit from children less than 12 years of age. The expenses for tournament equipment are substantially less than for preteenagers. Competitors at the Junior National competitions must be at least 15 years old; while Olympic competitors must be at least 17 years old. [14] Taekwondo businesses have a means to control the digital curtain for their customers and users. The systems lifecycle solution is to adapt current business models to satisfy customer and user expectations. By spreading the expenses for tournament equipment over a larger based of non-tournament participants, lowers the financial burden on those who desire access through the digital curtain.

\section{SYSTEMS SOLUTIONS FOR THE PROBLEM}

Technology management is a way to control the digital curtain. Instead of capitulating to the unrequited interests of tournament competitors, business owners could revamp their business plans to engage in new partnerships, revenue sharing, enhanced offerings of services, and reallocation of profits. Enabled by MBSA, technology management reveals a strategy to sustain profitability while making the tournament technology available to the business customers and users so that the digital curtain opens. Forging a change from a systems business model to a system of systems business model or a civic business model will enliven the Taekwondo business, increase opportunities to include greater numbers of participants, and avoid business closure or bankruptcy.

\section{A. Discussion}

MBSA recognizes two differentiable sets of imperatives to determining the consequences of a substantial cost increase per customer on the internalities and externalities of a business-as-system [10]. Regardless of how that extra cost is allocated and paid, the apportionment to the business systems is borne by all the stakeholders of the business over the lifecycle of the stakeholders and the lifecycle of the business. Since, training to participate in competitive tournaments is a primary means of attracting and retaining customers (payers) and users (participants), a stakeholder's "want" or "need" for competitive training could be either satisfied or ignored. If ignored, the business, customers, and users may all lose an opportunity to work together, to benefit from each other's 
wants and needs, and to fulfill the fundamental directive of business - helping people for mutually derived value. If the stakeholders concur to incorporate a technology into the internalities and externalities of the business, there are only two strategies by which to deal with an increase in cost for any stakeholder - either share the increase amongst the stakeholders with a certain value preference that is allocated according to achieving minimum loss to the system; or alternatively, increase the number of stakeholders who have different value preferences from the initial set of stakeholders such that the minimum loss is apportioned to different value preferences. The concept of 'achieving minimum loss' means that each of the stakeholder's absorb (pay) an amount that when distributed across all stakeholders results in the lowest mathematical loss of money to each stakeholder [10]. The concept of "apportioned to different value preferences" means that if the initial group of stakeholders are not be willing to accept additional financial burden(s) to gain access to the digital equipment, then the business can change their business model to include partnering with other businesses that find mutual value working with the stakeholders who want access to the digital equipment. For both of these concepts, the systems perspective of minimum loss to all stakeholders is the imperative for business internalities and externalities.

The crux of integrating technology into an organization is having the practice and skills to plan, direct, control, communicate, and team-build [10] the technology into the infrastructure and sidle seamlessly into the socioeconomic conditions to achieve unabridged interoperability that then gives rise to organizational excellence and achievement. The success of technology management is to raise the digital curtain to let more customers and users of products and services benefit from harvesting efficiencies and investing in selfimprovement. The digital curtain works as a controlled wall that mediates the flow of information by switching on and off who can and who cannot participate. This flow of information serves as a gateway to digital learning, innovation, and creativity. Technology management defines the interactions that businesses and individuals have with the digital curtain. The digital divide refers to the gap between the members of society without ready access to computers or Internet and those that have ready access. In contrast, the digital curtain shows how access to digital technology can be managed.

This paper extends the sematic notion of business taxonomy to systems and system of systems, specifically the homeomorphic structures of businesses - the system or the system of systems. By using MBSA, owners and managers may adjust their business models to open the digital curtain. At a more personal level, the digital curtain reflects the Parmenides portrayal of unity (of society) where ready access - exists, does not exist, or cannot exist. The systemic nature of business can be controlled shrewdly to provide reciprocal benefit for all business stakeholders by raising or lowering the digital curtain through strategies of technology management.

\section{B. Business as systems and systems of systems}

A business is distinguished by its capacity to find and support customers in various niches with product and service offerings, to grow and sustain market share, to attract and maintain qualified personnel, and to participate in partnering and contractual relations, for example. Heretofore, business topologies could differ by type (manufacturing, service, merchandizing, or hybrid); by form (corporation, limited liability corporation, partnership, sole proprietorship, or cooperative); and by kind (for-profit, nonprofit, or government). This paper incorporates a new, high-level homeomorphism in business topology - whether the business is a system or a system of systems. While systems and system of systems have a great deal of similarity they are not at all the same [10].

For systems to be systems and businesses to be systems, these all must show homeomorphic correspondences and isomorphic properties. Homeomorphisms demonstrate correspondences (with information loss) between one aggregation of components (groupings) and another aggregation of components. At a high level of abstraction, systems are said to be like-categories, business as system are similarly like-categories. Although there are differences between businesses, homeomorphisms are a requirement for systems and systems of systems (and consequently, for businesses that are systems and systems of systems). Since the instances of a more comprehensive mapping between businesses exposes specific one-to-one correspondences for being systems, it should be expected that such properties are structures-preserving isomorphies. Isomorphies are the one-toone correspondences (i.e., equality) between the elements of every business that are essential to the survival of the business, where every element affects every other element in the topology. An isomorphism is both a mapping of one to an other, as well as from an other to one. If an object is nonessential to the functioning of a system, it should neither be part of the system nor the business. To carry nonessential elements, is to detract from the sustainability of the business (or system). Business structures are homeomorphic and isomorphic.

\section{a) Systems}

A system is any grouping of bounded, interacting physical objects that are adaptively stable and agile, and show intrinsic, nonreciprocal emergence. A system is self-supporting group of physical objects and processes that continues to demonstrate certain traits that are different from groupings of objects that are not a system (Notasystem) and groupings of systems that are systems of systems. Systems are dynamically stable constantly moving energy, matter, material wealth, and information (EMMI) [10] to adjust to changes in internal and external inputs of EMMI. It is essential for a system to be interactive with its environment and its context (e.g., with other systems, objects, and processes). External interactions resupply the EMMI necessary to sustain a system. Internally, a system's physical objects are near continuously interacting with each other.

A system has action, i.e., does something or is active. A system's actions derive from the interactions of its components. 
A system has interdependent parts. Unlike notasystems, systems have in common their satisfying all four isomorphic properties. The reasons are due in part to a system having (1) interdependent parts, (2) interactions mediated by control mechanisms, (3) dynamic stability, which is essential for metastability, and (4) showing nonreciprocity in coupled multimode interactions [10].

Systems can be conglomerated into an integrated, interoperable grouping of systems that achieves a set of metasystem functions in which all constituent systems participate to varying degrees. A system of systems is in actuality not a system in the same manner that a system is a system [10]. Systems must satisfy the four isomorphic properties of a system to be a system (in this instance, a business). But while a system is a constituent of a system of systems the systems must be able to act individually in a reciprocal way to reverse the relations by agreement. A system cannot be prohibited from disengaging from the system of systems or that constituent system becomes an inescapable part of the whole to the extent the system has full reliance on EMMI for its existence [11]. Each system must be allowed to revert to its pre-system of systems self and be able to resume independent operations if it cancels the arrangement by which it became a member of the system of systems.

\section{b) Notasystem}

A notasystem is a set of objects that interact in such a way to keep being what it is and doing what it does by not being significantly affected by interactions from outside its boundaries [10]. Notasystems are stable - long-term stable. A rock (notasystem) has no action - does nothing and cannot do anything without being acted upon by something else. The composition of a rock is solid mass of grains of different mineral matter that undergo chemical reaction when compressed. Often, a small amount of organic matter is consolidated into the mix. The rock's formation involves processes demonstrate nonreciprocal emergence. However, a rock does not exhibit metastability, internal agility, or external adaptability. As such, a rock has no independent means for motion, no mechanisms by which to extract energy or matter from its constituent parts, and no means of increasing its size, separating itself, or dividing. A rock is notasystem.

\section{c) System of Systems}

A system of systems must respect all systemness of its constituent systems and do no harm to irreparably change them. The requirement of "do not harm" to its constituent systems is the first condition for all systems of systems. The other four conditions for systems of systems are that each constituent system must simultaneously satisfy the four conditions for systems; the agglomeration of constituent systems must be metastable; the agglomeration of constituent systems must have internal agility to move EMMI between the constituent systems; and the agglomeration of constituent systems must have external adaptability to behave in a systems manner with the other constituent systems. The emergence that results from the interactions of the constituent systems must be that of a system without the requirement to damage any of the constituent systems.

As a system of systems (system of businesses), no constituent business shall interact with another constituent business to harm each other or any other system of businesses. The emergent functions that enable a system of businesses will most certainly require each constituent business to expend EMMI. Each business that participates in a system of businesses will experience a loss for their lifecycle participation with the other constituent businesses. For a system of businesses, the decision to participate must be made by each constituent business based on the relative worth of that participation. Under most circumstances, it is self-defeating for a business to participate in a system of systems as a constituent system if the systems' participation may result to its detriment or in its complete demise. However, one constituent system may be comfortable with sacrificing itself for the good of the whole and therefore join the system of businesses with that as a possible outcome for their participation.

A conglomeration of businesses constitutes a system of systems if five isomorphic properties are satisfied. For systems, the four isomorphic properties are metastability, internal agility, external adaptability, and nonreciprocal emergence; whereas the five isomorphic properties to be a system of systems are metastability, internal agility, external adaptability, and non-reciprocal emergence-to sustain its systemic state, in addition to the system having reciprocal emergence with the system of systems [10-11], [19-20]. All five isomorphic properties of a system of systems must be satisfied simultaneously for a system to exist within a system of systems and for the system of systems to exist as a whole.

\section{COMPLEXITY AND INTEGRATION WITHIN MBSA}

The intent of MBSA is two-fold: (1) complexity can be implemented and evaluated within rational domains (principle of homeomorphisms); and (2) integrations and their associated interoperabilities result from reciprocal and non-reciprocal interactions (principle of emergence) [20-21]. MBSA builds on a theory of systems that describes the key determinants for sustainable businesses [10].

The cornerstone of MBSA is to recognize that functional performances are absolute as viewed in terms of limitations; and they are in flux as arbitrated by change in performances within those limitations. The dynamics of change are constrained by mechanisms that provide the system behaviors of a business. To carry out their mission, the business must be sensitive to both the limitations by which there is no more than the absolute, and the constraints from which the dynamics of exchange between constituent parts of the business supply and are supplied with resources. These resources EMMI. Control of these exchanges of EMMI is mediated by policy, rules, behaviors, and procedures - collectively relevant for the mechanisms that enable the operations of a business. Business owners and stakeholders are sensitive to the value and worth of the limited EMMI and changes in EMMI in anticipation of the consequences or reactions therefrom. 
All businesses have similar structures to achieve sustainable operations to make a surplus over expenses (or by definition, they are not businesses). These structures provide for access to EMMI (e.g., material wealth is capital) to finance the business startup, customers who provide the business revenues, the means to convert revenues into needed goods and services, relationships with others to provide needed goods and services, decisions to decide what is needed and what is not, mechanisms to moderate the flow of EMMI to build capacity, and communications to inform and be informed about activities and events that may damage or enhance the flow of EMMI. These structures are characterized by the physical objects and processes within the business as they are expressed by their separations, components as an equivalent class of togetherness, path connectedness, and compactness.

\section{A. Isomorphic properties of systems and systems of systems}

There are four isomorphic properties of systems and therefore four properties that are connately bred into a business. These business properties are inherent metastability of operations, external adaptability to outside action, internal agility to move EMMI, and nonreciprocal emergence that emphasizes the irreversibility of action. These four properties are the properties of a business as a system [10]. The nature of a business ensures the concept of business as system.

\section{1) Metastability}

Metastability is an isomorphic property whereby a business sustains systemic behaviors by being able to change, for example, from a state of lower anxiety to another state of higher anxiety, but returning to the initial state requires a different mechanism that used to attain the higher state. Continuing with the example of states of anxiety, laughter can help return people to a lower state of anxiety (which is quite different than the stressors that increased anxiety. Objects within a business can change from one state of being dynamically stable to another state of being dynamically stable, where the conditions to be in one state are different than the conditions required to return to the previous state. Dynamic stability means to be resistant to change from a given state, thereby implying that metastability is a more powerful mechanism that moves from one dynamically stable state to another dynamically stable state. The return path from a higher state of anxiety to a lower state of anxiety requires a different path, i.e., a different mechanism than taken from a lower state to the higher state. The property of metastability is required for a system, but not all processes and mechanisms need be metastable. Only some of the key activities must be metastable. And, even if an aggregation of objects has the property of metastability, the other three properties (following this paragraph) must also be operative for the aggregation to be a system. Metastability is a necessary isomorphic property that must be met for a system to exist [10] [22].

\section{2) Agility}

The second isomorphic property of a business results from its agility to move EMMI between internal physical objects to sustain its need for capacity utilization and capability. Moving EMMI requires interactions between objects. These internal interactions are also responsive to encounters with external physical objects. The sustained internal agility to move EMMI according to its needs is a necessary condition for a system. Internal agility to move EMMI is a necessary isomorphic property that must be met for a business to exist [10].

\section{3) Adaptability}

The third isomorphic property of a business is external adaptability to accommodate or insulate the aggregation from external influences that are inconsistent with sustainment. These external interactions may require the business to expend EMMI to respond, adapt, or accept incoming EMMI. For businesses, external adaptability to incoming EMMI is required in addition to isomorphic properties of internal agility and metastability [10].

\section{4) Nonreciprocality}

The fourth isomorphic property of a business is to show nonreciprocal emergence. Emergence is of two ilks reciprocal and nonreciprocal. Emergence results from any two interacting physical objects [10]. Reciprocal emergence means that interacting objects result in like-kind responses where each object reciprocates in mutual exchange. The result of reciprocal emergence is that changes made due to the exchange of EMMI revert to the pre-change states of each physical object, i.e., no change in the physical objects. Nonreciprocal emergence means that interacting objects result in irreversible change(s). With nonreciprocal emergence, for example, there may be no return EMMI, no mutual exchange of EMMI, or no like-kind response, i.e., physical object(s) are changed irreversibly after interaction. Nonreciprocal emergence that is artifactually constructed can be enforced by rules enacted by businesses. Nonreciprocal emergence is a necessary isomorphic property that must be met for a system to exist [10], [23-24]. All four isomorphic properties must be satisfied for a business - for a system.

\section{INTERPRETIVE INTEGRATIVE FRAMEWORK}

MBSA presents two canonical frames - object and process. The object frame abstracts a subset of classes within the object ontology and the process frame abstracts a subset of classes within the process ontology [11]. These subsets of classes form the taxonomy related to notasystems, systems, and systems of systems [11]. The ontologies and their respective taxonomies form a representation of a canonical interpretive integrative framework [20] which captures all allowable interactions between the two classes of taxonomy. This structuring provides a semantic model for to decode, interpret, and predict the consequences of interactions between the $3 \times 3$ matrix that comprises the interpretive integrative framework. The syntax for modeling systemic actions results from the allowable interactions stipulated in the direction of analysis through the row-column nine-nexus squares (see Figure 1 next page column left).

The interpretive integrative framework was first introduced in the context of a general theory of integration 
[12-13]. Then, the integrative framework was applied to the notional ontology for systems and system of systems for developing the rules of taxonomy and to demonstrate,

\section{PROCESS}

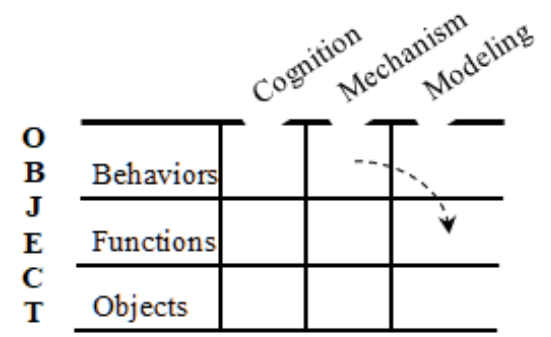

Figure 1. MBSA Interpretive Integrative Framework

"...flexible dimensionalities and proper atomic form to allow for integration according to the rules of part-whole mereology so as to capture all relationships between structures, delineate all processes, and stipulate every interaction between objects in both event-based and timebased contexts" [20]. This framework is of ontological origin and intent. The particular framing in two ontological domains grew out of the ideas in Stanislaw Leśniewski's "Foundations of the General Theory of Sets" [25-26]. A formal mereotopology foundation was developed for a general structuring of systems and system of systems. Through an expository framework of object-related and process-related concepts all interactions can be categorized. In the most general appreciation of epistemology, such a mereotopology framework that codifies the most comprehensive ontology represents all knowledge [27] [10] [19] interpreted Leśniewski's formal relationships between objects and processes by formulating an interpretive integrative framework that integrated the three dimensions of the process taxonomy along the abscissa axis with that of the three dimensions of the object taxonomy along the ordinate axis. All that are objects are objects; all that are processes are processes; all that are not objects are processes; all that are not processes are objects; all that are not objects or not processes cannot exist. Therefore, the three dimensions of objects are mapped to each of the three dimensions of processes, and vice versa. The intersecting frames of object dimensions and process dimensions forms the interpretive integrative framework. This framework of causal interactions and causal processes captures the totality of all objects, processes, and their actions [28].

\section{TEChNOLOGY MANAGEMENT (DEFINED BY MBSA)}

The modeling language used to describe the properties, traits, and attributes of MBSA is exact through its definitions [10] , [19] and their formal description through the mathematical logic of Leśniewski development of whole-part ontologies [25-26, [10-11], [19]. Applying the terms from MBSA provides a very general account of the nature of technology management. However, the nature of technology management is exclusively distinguished from all other disciplines by a very specific set of descriptors that indicate the uses and benefits of technology management and how to carry out the activities of technology management. In the most general sense, technology is that which extends existing capability to support and enhance functioning [19], [29], [30]. Functioning requires interaction between two objects, e.g., a person and a keyboard. By itself, technology is insufficient to indulge commercial acceptance. Tech mgmt. also needs to incorporate distribution channel expertise, operational prowess in moving goods and providing service, retail partnerships and end-user support to tailor the technology to the wants and needs of the customers and the users. In the case of taekwondo martial arts businesses, technology managers may strategize to lift and hold open the digital curtain for their customers and users of digital technology. As such, the technology managers must deal with uncertainty, ambiguity, and complexity [31]. Technology management must deal with uncertainties of not knowing the boundaries of acceptable use, clarify the ambiguities that derive from having to tailor the technology to specific uses other than those described in product documentation, and strip away the complexity by modularizing the amount and kinds of information necessary to convey the simple concepts buried within the morass of presentation and discourse. The work of technology management must focus on all aspects of the business to provide a sufficiency of products and services to a growing, but ultimately limited number of customers and users. Once a "new" technology is adopted to raise the digital curtain, the business must apply measures to ensure quality improvement across the organization, lower recurring costs, and extend the boundaries of the business to include their customers and the users. Ultimately, technology management must see the business customers and users as part of the business; must view the products as services and the services as products; must consider the lifecycle needs of all stakeholders as those of the business; and must be aware that every aspect of the business is meant to control operations by effective and efficient mechanisms. Importantly, dispositive power is not control, but rather representative of a mindset of stakeholders that only disposes of or surrenders EMMI according to policy or rules. Instead, all stakeholders are to be pro-active and diligent in executing their duties to the business to ensure EMMI is used according to the needs of raising and sustaining the digital curtain.

Through MBSA, the characteristics, nature, and operational aspects of technical management are constructed to understand the business from its fundamental notions and actions. The ontological structure of MBSA offers the means to suggest various interactions that may give rise to change in the organization. The amount of change can be quantified by calculating the losses incurred, assuming a relationship between the objects (and their variables) that make up the interaction. The idea that an organization can change and be understood in terms of the fundamental interactions within the boundaries of the organization forms the basis for understanding and characterizing the organization. The idea that an organization can change and that change can be predicted is predicated on being able to quantify the losses if the organization does and does not make the change. These calculations rely on the normalization of a general loss function 
to the particulars of the organization (and more specifically to the key interactions that must take place for the change(s) to occur. The general loss function is described in detail [10] and it use is exampled [32]. When the organizational is imbued with technology, the emergents that result from people interacting with people and people interacting with physical objects become the context and rationale for systemic behaviors. Functions are measureable aspects of the business and therefore indicators of the actions of organizations that represent technology. These interactions extend to all stakeholders in the business. In brief, actions resulting from technology embeddedness are the driving mechanisms that assume legitimacy for organizational action and fact. These mechanism offer a new perspective on technical management - one suggesting that behaviors of stakeholders who hold the subtle threat of truculence are essential to organization and project success.

\section{BUISNESS MODEL FROM THE MBSA PERSPECTIVE}

A general business model consists of all the basic interdependent objects and processes required for running an organization as a system [33]. A business model attempts to capture the structure and flow of EMMI into and within a business. In the case of martial arts businesses, the organization create, propose and deliver "flow", a value for its martial arts instruction provided to customers and users and potential participants. That flow (as mediated by various internal and external mechanisms) represents the use of resources and exchange of goods and services with customers, business affiliates, partners, vendors, and stakeholders. The grand orchestration of "flow" is strategy. Altering the type, form, kind or homeomorphism of a business can change the partners and contractual relations, control and use of assets, roles and responsibilities in decision making, and economic outcomes and consequences. The business model reflects the systemic nature of operations and management and strategy. Specifically, technology management of changes in the business model requires close attention to not only the historical structure and "flow" but also the consequences of new relations and their dynamic impacts on decision making. MBSA makes processes transparent to detection and analysis, reveals loss and delay, and suggests opportunities aligned with operations. A seemingly minute yet meaningful change may highlight a privileged advantage within a digital market segment (given certain technologies) or upend the norms of business and shutter the digital curtain. Strategy needs to reflect all aspects of "flow".

A strategy is a set of goals enacted by major policies followed by cohesive objectives and then carried out duly according to rules of thumb and rules of dumb. For a business to change its strategy it must alter and pursue a business model to orchestrate "flow", and how to evaluate the results of "flow" (strategy).

MBSA is used to formulate a set of evaluation criteria that directly addresses inherent complexity of the relations that are to be measured along with the degree of transparency into the causal actions that underpin the results. For example, the evaluation should expose the context that caused the observed results, where the expected results were not observed, and expose expenditure excesses and parsimony relative to results in contrast to expectations. Fundamentally, did the strategy work or not and why? Was the strategy ineffective, poorly implemented, or absolutely correct? Were new opportunities discovered, was sustainment achieved, and is the business value increasing? These and many more questions should be answerable from MBSA. The design of the evaluation instrument must be integrally reflected in the business operations, architecture, and model [34].

Using MBSA, the four isomorphic properties of systems are engrained in the fabric of the business strategy and the skeleton for evaluation. The evaluation instrument should be based on the four isomorphic properties for systems. The outcome of the evaluation instrument must be a complete and accurate interpretation of the strategy, assumptions, risk, and timing. Validity of the evaluation instrument is achieved through a correlation of the mechanisms at work within the business that drive the outcomes of strategy. The measure of effectiveness for the strategy is objectified by the sum of losses of EMMI used to achieve the results of strategy. The quantitative analysis is performed on the functional performances that are correlated to the goals and objectives.

The four isomorphic properties of systems are cast into phraseology that maps the systemic nature of MBSA strategy into the evaluation instrument that could be used for business.

The language of MBSA is extremely precise to form a twodimensional concatenation of terminology where every definitional is consistent with every other term in the concatenation. This concatenation is the result of applying the formalism developed by Leśniewski in his general mereology of objects and processes [25-26]. The evaluation tests (see Table 2 below) are described to indicate their utility in forming business strategy. The MBSA language relates the four elements of the business strategy (indicated by "Tests" to the four isomorphic properties that are necessary for a system metastability, internal agility, external adaptability, and nonreciprocal emergence. In turn, the MBSA language is mapped as gently as possible to the language of business. Many of the business concepts for strategy are not shown explicitly. However, the work of Rumelt [35] exposes additional relations in business that are often use to explain in different forms how strategy is described in various manners. Herein, is an issue when reading the general literature on business with or without specialization in a discussion concerning strategy. The language of business benefits from multiple perspectives and the latest craze that attracts the attention of business. The language of business needs to be translated into the précising definitionals of MBSA. The general descriptions, typical of business are readily understood for what they are-absolutes with the model of MBSA. 
TABLE 2. MBSA MAPPED TO BUSINESS LANGUAGE

\begin{tabular}{|c|c|c|}
\hline Evaluation & MBSA LANGUAGE & Business Language \\
\hline Tests & Isomorphic Properties & Strategy [35] \\
\hline Cohesion & Coherence in action & $\begin{array}{c}\text { Consistency of goals and } \\
\text { policies }\end{array}$ \\
\hline Congruence & $\begin{array}{c}\text { External adaptability with } \\
\text { internal agility to respond to } \\
\text { changes }\end{array}$ & $\begin{array}{c}\text { Adaptive to external } \\
\text { changes with internal } \\
\text { changes }\end{array}$ \\
\hline Advantage & $\begin{array}{c}\text { Scalability of nonreciprocal } \\
\text { emergents to gain network } \\
\text { externalities }\end{array}$ & $\begin{array}{c}\text { Creation and } \\
\text { sustainment of } \\
\text { competitive advantage }\end{array}$ \\
\hline Expediency & $\begin{array}{l}\text { Redundancy from } \\
\text { metastable operations to } \\
\text { sustain action }\end{array}$ & $\begin{array}{l}\text { Work within usable } \\
\text { resources and do not } \\
\text { create unsolvable issues }\end{array}$ \\
\hline
\end{tabular}

\section{Systemic Business MOdELS}

\section{A. Case Studies}

This research used case methods to differentiate a business modeled as a system and a business modeled as a system of systems. Several martial arts organizations were selected as cases to compare in terms of kinds of businesses for-profits and non-profits. Prototypical martial arts organizations with the most available sources of data were selected to represent business models that reflected the same type with variability in the form, kind, and homeomorphism. The characteristics of the business legal status as a corporation, sole propiertorship, or partnership, for example, were not considered in preparation of this paper. This research emphasized the differences in the businesses based on for-profit / nonprofit and system / system of systems being the typical of combination of factors that represent the common structures and operations of the martial arts business. The form of the business had little to do with the size of the taekwondo businesses. After comparing the key elements of the different business models before and after they changed their strategy, the businesses were evaluated in terms of the increase in number of participants and whether the digital curtain was raised or lowered. In general, customers of martial arts businesses have a sense for the value of a product or service that is expressed in their willingness to buy that product or service. From the perspective of the digital curtain, these customers are either or resigned to be disenfranchised by the closed digital curtain.

\section{B. Bayside Martial Arts, for-profit-System}

\section{1) Situation Assessment}

Bayside Martial Arts operates as a stand-alone venture. To make a profit Bayside must locate in a low-rent area within an urban area with 25,000 to 50,000 population have no affiliations with other martial arts business, pay for the annual liability premium, regular maintenance, and repair of their studio and locker rooms. Head instructor (owner) pays a small remuneration to instructors and pockets the remainder after expenses. Instructors (volunteers) often have day jobs and volunteer to teach classes after work and on weekend. Volunteers benefit by working to promote higher ranks. These volunteer instructors reduce the average participant to instructor ratio to $6: 1$. Customers (participants or parents of the youth participants) pay an initiation fee and a monthly membership fee for lessons, in addition to one-time payments for uniforms, belts, and sparring and practice equipment, e.g., kicking shields and kicking paddles. Customers find value in expecting their children to improve in focus, self-confidence, respect, and physical health. Users find value from enjoying new friendships and camaraderie from their instructors and other participants, promotion in the belt advancement testing for social recognition from peers and competition to win medals at tournaments. The strategy of for-profit businesses (system) is to sustain operations to include providing discounts to existing customers for families participation with the per head fee less as the number of family members increase; receiving a monthly discount if participants take advantage of automatic electronic fund transfer in paying their monthly membership fee; pricing slightly below competition; and offering non-martial arts classes, such as yoga, that have payas-you-come pricing instead of a monthly fee.

The activities shown in tracking the flow of money for Bayside Martial Arts are captured in a MBSA Flow Diagram [12] (see Figure 2 below). Arrows indicate the flow of money from tail to head. The tail of the arrow with a dollar (\$) sign refers to the provider of funds for the financial activities, and the head of the arrow with a dollar sign refers to the recipient of funds. The tail of the arrow without the dollar (\$) sign refers to the providers of the resources including people, knowledge, equipment, and facilities. The head of the arrow without the dollar sign refers to the recipient of the resources. Note, volunteers provide instruction to the Bayside Martial Arts, but do not participate in the flow of money. NOTE: all figures use the same descriptors for interactions, arrows, and indications of flow of money.

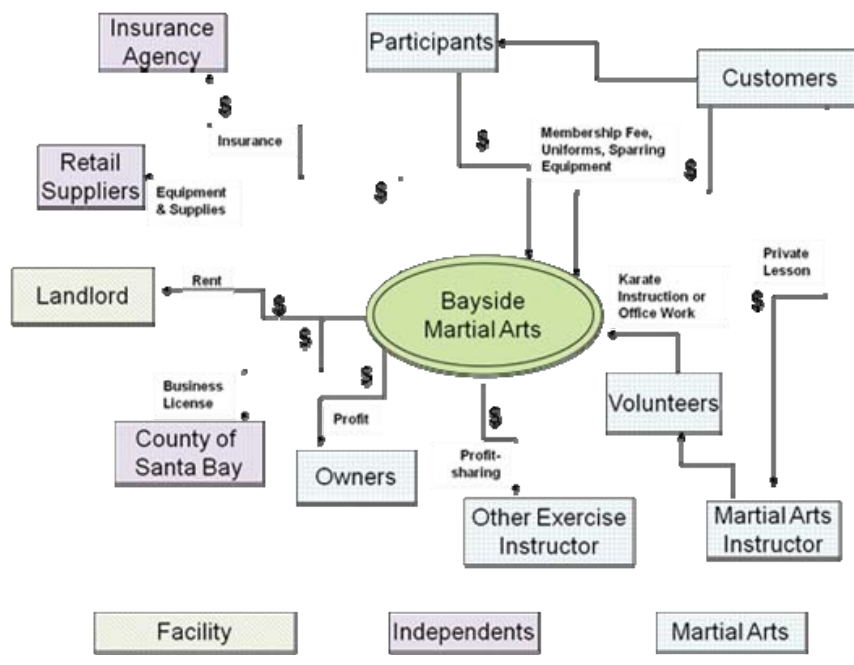

Figure. 2 Business Model for Systems (for-Profit)

\section{2) Strategy}

Examples of the strategy to change system, for-profit into a system of systems, for-profit (see Figure 3 next page, left column) include:

- Change for-profit business model to a for-profit system of systems by partnering with digital technology providers for taekwondo tournament 
competitions to reduce costs of technology in exchange for pre-market testing and user opinions and experiences, and

- Change for-profit business model to a for-profit system of systems by partnering with another for-profit business to mutually increase product and service offerings to attract new participants for both businesses.

\section{3) Results of Strategy Change}

- No change in strategy for Bayside Martial Arts Bayside ceased operations.

\section{River Martial Arts, for-profit-System of Systems}

\section{1) Situation Assessment}

River Martial Arts operates within a system of systems business structure by working with other businesses to make a profit (see Figure 4 right column). The systems within this system of systems enjoy mutual benefits through a network of organizations that, by contract, share the profits, resources, information, facilities, and people in providing martial programs. A private gym and martial arts organization mutually benefit by sharing facilities, enrolling members, and splitting revenues. The relationship prospers from an otherwise shared investment in extensive facilities and healthrelated programs for members. Steady growth in membership helps to sustain both businesses in the system of systems. All instructors are paid, albeit only a small remuneration. The owner of the River Martial Arts receives a proportionally greater share than the other instructors.

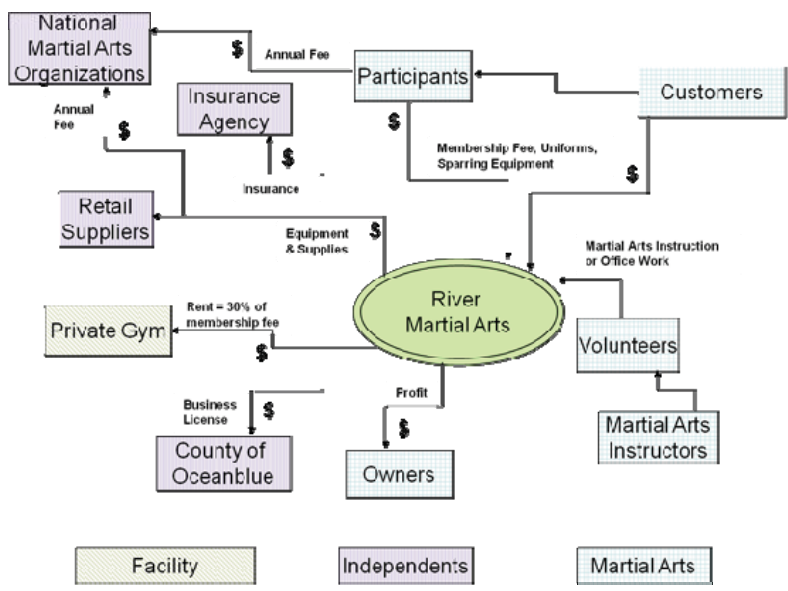

Figure 3. Business Model for System of Systems (for-Profit)

Martial arts customers find value in a significantly larger array of services, equipment, and course offerings beyond what is offered by martial arts businesses with system homomorphic structure as long as that business enables lifting of the digital curtain. Customers also find value in expecting their children to improve in focus, self-confidence, respect, and physical health. Users find value from enjoying new friendships and camaraderie from their instructors and other participants, promotion in the belt advancement testing for social recognition from peers and competition to win medals at tournaments. The strategy of for-profit businesses (system of systems) is to sustain operations to include participants in taekwondo becoming a member of the gym and taking advantage of the gym's policies regarding discounts to existing customers. As with the systems' business, the martial arts organization pays their annual liability insurance premium

\section{2) Strategy}

- Change for-profit business model to a for-profit system of systems by partnering with digital technology providers for taekwondo tournament competitions to reduce costs of technology in exchange for pre-market testing and user opinions and experiences.

- Change for-profit business model to a for-profit system of systems by partnering with another forprofit business to mutually increase product and service offerings to attract new participants for both businesses.

- Change for-profit business model to a for-profit system of systems by partnering with private gym to mutually increase product and service offerings to attract new participants for both businesses.

\section{3) Results of Strategy Change}

Change in strategy for River Martial Arts - at business startup, partnered with a private gym to mutually increase product and service offerings to attract new participants for both businesses. Started with 0 participants and grew to 50 participants.

\section{Neighborhood Martial Arts, Non-Profit, System}

A non-profit business model operated as a system exists in the martial arts industry but without a sufficiency of income, that business would struggle to survive. As a 501 (c) (3) organization, it is exempt from paying taxes on their profit from its monthly membership fees paid by its customers. All instructors volunteer to teach classes without pay. Every instructor has an alternative income. Monthly fees are used mainly to pay for the annual insurance premium to protect the non-profit from possible liability claims for injury or death, for the regional standards organization for promotion and instruction criteria as well as to the national standards organizations. To the same extent as the other structures of businesses, value to customers and users is gained to improve in focus, gain self-confidence, to instill respect, and promote physical health. Value to users includes friendship and camaraderie from their instructors and other participants, promotion in the belt advancement test for social recognition from peers, competition to win medals at tournaments. The strategy to sustain the non-profit business model is to involve family members as volunteers, every participant lending their efforts to foster friendships and a sense of belonging - as much a community service under the common interest of martial arts. 


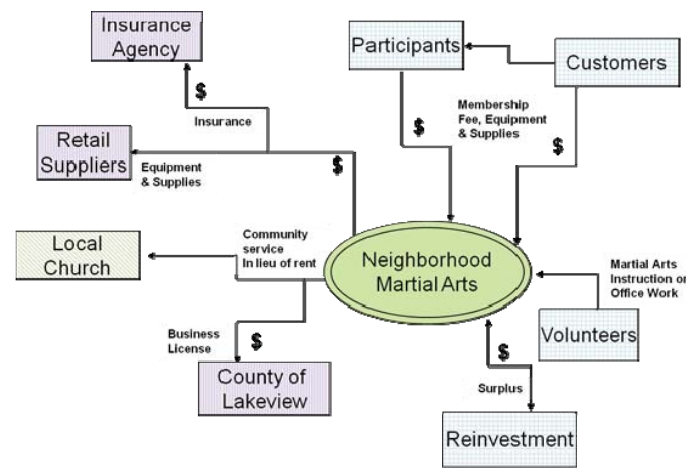

\begin{tabular}{lll}
\hline Facility Independents \\
\hline
\end{tabular}

Figure 4. Business Model for System (non-Profit)

\section{1) Strategy}

- Change business model to a system of systems by partnering with another like-kind business to mutually increase product and service offerings to attract new participants for both businesses.

- Change business model to a system of systems by spawning additional businesses that have same management (shared), same style of instruction, and centralized belt promotion

\section{2) Results of Strategy Change}

Change in strategy for Neighborhood Martial Arts - created additional semi-independent businesses that were geographically dispersed.

\section{E. Neighborhood Martial Arts, Non-Profit, System of System}

The non-profit Community Martial Arts operates as a system of systems - a 501 (c) (3) organization (see Figure 5, next column). While exempt from paying taxes on their profit, all monies collected are paid to cover cost of insurance, fees to retain memberships in governing standards' organizations, and subsidies for competition and belt advancement tests. Often the Community Martial Arts holds their instruction classes at a religious facility. Instead of paying rent, the martial arts organization provides community services through the religious facility such as semi-annual clean-up of the facility and providing volunteers for the religious gatherings and events. This kind of martial arts organizations does not have an owner, but rather a founding instructor(s) who has help found like-kind martial arts businesses that may be scattered over a large geographic distance. Each organization within the Community Martial Arts is individually-run. The lead instructors work as a team toward improving physical techniques and mental integrity of all participants in all of their individually-run martial arts businesses. All of the lead instructors are black belts certified by the national standards organization. None of the leaders receive monetary reward for providing instruction to the participants. Every instructor has an alternative income. There is a nominal monthly membership fee to cover the annual insurance premium fees and fees to the regional standards organization for promotion and instruction criteria, as well as to the national standards organizations.

Community Martial Arts purchases inventory for uniforms or sparring protective gear and sell to participants at a nominal increase to cover costs. Much of the expendable equipment is purchased by participants and loaned to new participants, again to mitigate and shield the cost of participation at the beginning of the participant's participation in the business. As the participants decided to stay, they buy their uniforms and equipment directly from the suppliers. It is through this sharing of required equipment that long-term dedication to the idea of the non-profit aspects are reinforced and perpetuated over, now nearly twenty-five years for this group of martial arts businesses.

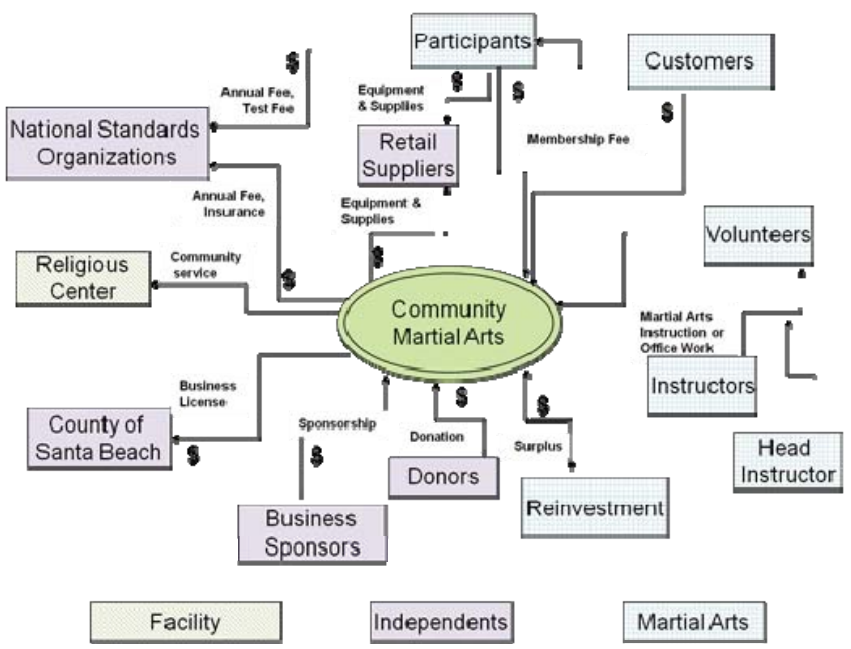

Figure 5. Business Model for System of Systems (non-Profit)

\section{F. Summary Results of MBSA Strategies and Outcomes}

Taekwondo martial arts businesses that faced controlling access to the digital curtain made decisions that dramatically changed the outcomes of their businesses. The time and effort to establish a system of systems partnership with an organization outside the immediate area prompted the Bayside business to close. From the experience of an entrepreneur choosing between starting the River business as a for-profit system or a for-profit system of systems, chose the system of systems - a long-term better decision. When faced with a constant turnover in participants due to the transient nature of Neighborhood's business environment, the long-term solution was to move from a non-profit system to a non-profit system of systems. The decision to change strategy and transition from a system to a system of systems (regardless of the structures of business) puts in place greater economic stability. Greater lifecycle stability adds to the economic prowess of the business and keeps open the decision to open or close the digital curtain. 
TABle 3. InCREASE IN PARTICIPANTS (SYSTEMS TO SyStems OF SYSTEMS

\begin{tabular}{|c|c|c|c|c|}
\hline $\begin{array}{c}\text { Martial Arts } \\
\text { Business }\end{array}$ & $\begin{array}{c}\text { System or } \\
\text { System of } \\
\text { Systems }\end{array}$ & $\begin{array}{c}\text { No. Participants } \\
\text { (before strategy) }\end{array}$ & $\begin{array}{c}\text { No. Participants } \\
\text { (after strategy) }\end{array}$ & $\begin{array}{c}\text { Short-term } \\
\text { Effect on } \\
\text { Digital Curtain }\end{array}$ \\
\hline Bayside & System & 75 & 0 & Closed to all \\
\hline River & $\begin{array}{c}\text { System } \\
\text { of } \\
\text { Systems }\end{array}$ & 0 & 50 & $\begin{array}{c}\text { Not yet } \\
\text { opened }\end{array}$ \\
\hline $\begin{array}{c}\text { Neighborhoo } \\
\text { d }\end{array}$ & $\begin{array}{c}\text { System } \\
\text { of } \\
\text { Systems }\end{array}$ & 25 & 150 & $\begin{array}{c}\text { Not yet } \\
\text { opened }\end{array}$ \\
\hline
\end{tabular}

The economic means to offer an open digital curtain is shown to increase the number of participants (see table 3 below), which corresponds with a commensurate increase in revenues. Profitability increases for business owners and reinvestment in the business increases for nonprofits.

\section{CONCLUSion}

Technology management is a strategic requirement for keeping the digital curtain open to all participants. This paper shows that digital technology is welcomed as a catalyst to inspire small business owners to determine how they can adapt their business models to benefit themselves and their customers and users. Implementing a systems strategy based on the MBSA shows how to forge new business relation and partnership. No business should fall victim to progress.

MBSA is based on précising definitionals and Leśniewskian mathematical formalisms for the mereology of objects and processes. The ontologies of objects and processes are constructed into two frames that pose taxonomy for objects of physical objects, functions, and behaviors; and the taxonomy for processes of cogitating, mechanizing, and modeling. The use of flow (strategy) to describe all interactions resulting in functions is completely structured within the interpretive integrative framework (comprised of the ontological frame of object intersecting with the ontological frame of process. The technology management of accessing and sustaining the digital curtain (for example) is completely characterized and represented within the ontological framework. The explanative and predictive power of MBSA is shown in brief in this paper.

For the technology manager, the principle of managing the digital curtain can be stated as: the thrill of affordability cannot be seen as a deterrent for accessing and using digital technology because the allure of technology is a stronger elixir.

\section{REFERENCES}

[1] C. Barnard, The Functions of the Executive. Harvard University Press, Cambridge, MA., 1938, pp. 77-78.

[2] L. von Bertalanffy, "General System Theory", Emery, F.E. ed. in General System, Yearbook of the Society for the Advancement of General System Theory, 1956.

[3] W. R Ashby, "Effect of Controls on Stability," Nature (London), vol. 155, no. 3933, pp. 242-243, Feb. 1945.

[4] Wiener, Cybernetics, New York: Wiley, 1948.
[5] L. von Bertalanffy, "General System Theory - A new approach to unity of science," Human Biology, pp. 302-361, 1951.

[6] W.R. Ashby, "General Systems Theory as a New Discipline", Emery, F.E. ed. in General Systems (Yearbook of the Society for the Advancement of General Systems Theory), 1958, vol. 3, pp. 1-6.

[7] G. J. Klir, An Approach to General Systems Theory. New York: Van Nostrand Reinhold, 1969.

[8] J. G. Miller, Living Systems. New York, McGraw-Hill Book Company, Inc. 1978.

[9] L. von Bertalanffy, General System Theory: foundations, development, applications. New York, George Braziller, 1968.

[10] G. O. Langford, Engineering Systems Integration: Theory, Metrics and Methods. Boca Raton, Florida, CRC Press/Taylor \& Francis. 2012.

[11] G. O. Langford. "System of Systems Process Model," in Engineering Emergence: A Modeling and Simulation Approach, L. Rainey and M. Jamshidi, Eds. Boca Raton, Florida: CRC Press/Taylor \& Francis. 2018 (in press)

[12] T. S-Y. Langford, "Building a Sustainable Business Model: analysis of martial arts organizations from a system and system of systems perspective," M.S. thesis, Dept. Recreation and Tourism., Cal-State Univ., East Bay, Hayward, CA, 2014. Available: https://www.researchgate.net/publication/269334790 BUILDING A S USTAINABLE BUSINESS MODEL AN ANALYSIS OF MARTIA L_ARTS ORGANIZATIONS FROM_A_SYSTEM_AND_A_SYSTE M OF SYTSTEMS PERSPECTIVE

[13] I. Cho, "A multi-group analysis of the effects of the values from training in Taekwondo on the academic life and social attitudes of American students," Ph.D. dissertation, Kyung Hee University, Seoul, Korea, 2015.

[14] J. Han, S. Min, J, Hwang, P.D. Hite, W, Bae, (2016, Jan - Mar). A Delphi Method Analysis of Managemenet Strategies for Taekwondo Centers in the United States, Global Sport Business Journal 2016, 4(1). Available: http://www.gsbassn.com/Journal/Vol4-1/GSBJ-Vol4-Iss1Han-pp23-46.pdf

[15] Sports Club Advisors, (2018) Industry Snapshot. IBIS World Reports (2014)-Products and Services Segmentation from Simmons Market Research. Available: http://sportsclubadvisors.net/martial-arts-clubsindustry-snap-shot/

[16] M. Elshikh, Digital Equipment Rental, International Martial Arts (2018). Available: http://imatkd.com/martial-arts-rental-systems/

[17] Daedo, Daedo Electronic Scoring System (2018). Available: https://www.tkdscore.com/248.html

[18] J. Pierson, Tackling Social Exclusion. London: Routledge 2001

[19] G. O. Langford, "Toward a General Theory of Systems Integration: Research in the Context of Systems Engineering," Ph.D. dissertation, Defence and Systems Institute, School of Electrical and Information Engineering, University of South Australia, Mawson Lakes, Australia, 2012.

[20] G. O. Langford and T.S-E. Langford, "The making of a system of systems: Onology reveals the true nature of emergence," in Conf. Proc. $201712^{\text {th }}$ Annual System of Systems Engineering Conference IEEE Int.

[21] G. O. Langford. "Phenomenological and ontological models for predicting emergence," in Engineering Emergence: A Modeling and Simulation Approach, L. Rainey and M. Jamshidi, Eds. Boca Raton, Florida: CRC Press/Taylor \& Francis. 2018 (in press).

[22] F. den Hollander, "Three lectures on metastability under stochastic dynamics," in Methods of contemporay mathematical statistical physics, M. Biskup, A. Bovier, F. den Hollander, D. Ioffe, F. Martinelli, K. Netocný, C. Toninelli, and R. Kotecký, Eds. Berlin: Springer, 2009, 124.

[23] L. Ranzani and J. Aumentado, (2015). Graph-based analysis of nonreciprocity in coupled-mode systems. New Journal of Physics, 17(023024), Institute of Physics, Deutsche Physikalische Gesellschaft). Available: http://iopscience.iop.org/journal/1367-2630

[24] L. Ranzani and J. Aumentado, (2014). A geometric description of nonreciprocity in coupled two-mode systems. New Journal of Physics, 16(103027), Institute of Physics, Deutsche Physikalische Gesellschaft). Available: http://iopscience.iop.org/journal/1367-2630 
[25] S. Leśniewski, 1916. "Foundations of the General Theory of Sets, I", in Stanislaw Leśniewski: Collected Works, S. Surma, Stanislaw et al. Eds. [Nijhoff International Philosophy Series, 44] Dordrecht: Kluwer Academic Publishers, 1992: 129-173.

[26] S. Leśniewski, Leśniewski’s Lecture Notes in Logic. 1988. Ed. by J.T.J. Srzednicki and Z. Stachniak. Dordrecht: Kluwer.

[27] J. F. Sowa, Knowledge Representation: Logical, Philosophical, and Computational Foundations. Pacific Grove, CA, Books/Cole, 2000.

[28] G.O. Langford. "Verification of requirements: system of systems theory, framework, formalisms, validity. 27th Annual INCOSE International Symposium," IS 2017, International Council on Systems Engineering, Adelaide, Australia, July 15-20.

[29] R. E. Holloway, and J. Ohler, "Distance education in the next decade" 1991, in G.J. Anglin, Ed., Instructional technology, past, present, and future. Englewood, CO: Libraries Unlimited, Singapore 2007 pp. 25966.

[30] G. O. Langford, and H.L. Lim, "Predicting and Assessing Disruptive Technologies Using Event Space Modeling”, Paper No. 40, Paper presented at the Asia-Pacific Systems Engineering Conference, March, Singapore, 2007.

[31] T.A. de Silva, P. S. Leonardo, Sept./Dec. 2009, "New production development projects evaluation under time uncertainty," Pesquisa
Operactional, vol 29, no. 3, Rio de Janeiro. Available: http://www.scielo.br/scielo.php?script=sci arttext\&pid=S010174382009000300003)

[32] G. O. Langford, "Maintenance Scheduling Using Systems Engineering Integration," in Conf. Proc. $201626^{\text {th }}$ Annual INCOSE International Symposium, Edinburgh, Scotland.

[33] S., Poisson-de Haro and D. Montpetit, (2012). "Surviving in times of turmoil: Adaptation of the Theatre Les Deux Mondes business model," International Journal of Arts Management, 14(3), 16-31. Available: http://www.gestiondesarts.com/en/surviving-in-times-of-turmoiladaptation-of-the-theatre-les-deux-mondes-business-model/

[34] Centre of Excellence for Evaluation, Theory-Based Approaches to Evaluation: Concepts and Practices, Expenditure Management Division, ISBN: 978-1-100-20593-9, 2018. Available:

https://www.canada.ca/en/treasury-board-secretariat/services/auditevaluation/centre-excellence-evaluation/theory-based-approachesevaluation-concepts-practices.html

[35] R. Rumelt, "The Evaluation Of Business Strategy," in Business Policy and Strategic Management, 3rd ed, W. Glueck Ed. New York: McGraw Hill Publishing, 1980. 